\title{
Fractal Structure of Microcrystalline Cellulose Obtained by Method of Spray Drying
}

\author{
Michael Ioelovich* \\ Celdesigner Ltd, Israel
}

Submission: November 19, 2018; Published: December 17, 2018

*Corresponding author: Michael Ioelovich, Celdesigner Ltd, 2 Bergman St, Rehovot 7670504, Israel

\begin{abstract}
In this research, a fractal structure of beads of different sizes obtained by spray-drying of aqueous dispersions of microcrystalline cellulose (MCC) was studied. These beads are formed as a result of aggregation of rod-shaped cellulose nanocrystalline particles (CNP). It was found that increasing the average radius (R) of the formed MCC beads results in increased porosity (P) and reduced density ( $\rho$ ). The dependences of $\mathrm{P}$ and $\rho$ on scale factor $(\mathrm{R} / \mathrm{r})$ can be expressed by power-law equations: $P=P_{o}\left(\frac{R}{r}\right)^{E-D_{P}}$ and $\rho=d\left(\frac{R}{r}\right)^{\rho_{\rho}-E}$, where the fractal dimensions $D_{P}=2.887$ and $D_{P}$ $=2.986$ are close to Euclidean dimension $\mathrm{E}=3$ for three-dimensional space; $\mathrm{r}=3 \mathrm{~nm}$ is radius of cellulose nanocrystalline particles, $\mathrm{P}_{0}=0.03 \mathrm{~cm}^{3} / \mathrm{g}$ is porosity and $\mathrm{d}=1.585 \mathrm{~g} / \mathrm{cm}^{3}$ is true density (specific gravity) of CNP, respectively. Thus, with the increase in the size of formed MCC beads, the order in the packing of the beads is distorted conforming to theory of diffusion-limited aggregation process.
\end{abstract}

Keywords: Microcrystalline cellulose (MCC); Spray-drying; MCC bead; Size; Porosity; density; Fractal dimension

\section{Introduction}

It is known that various natural and artificial objects and phenomena can be considered as fractals, distinctive features of which are scale invariance (self-similarity) and fractional dimension [1,2]. The theory of fractals is widely used in engineering, mathematics, biology, physics, chemistry and other areas. According to this theory, the fractal dimension (D) of an object can be determined by logarithmization of power-law dependence of structure or property on scale factor. In particular, the theory of fractals was applied for description of structure and properties of such wide-spread natural biopolymer as cellulose and also of diverse cellulose materials.

For instance, cellulose fibers were studied by a method of low-temperature nitrogen sorption to measure the dependence of cumulative volume on radius of various pores expressed by the power-law function, from which the fractal dimension from 2.88 to 2.95 was determined [3]. In another research [4], the fractal structure of pores in various cellulose materials was studied by nitrogen and water vapor sorption methods; in the case of nitrogen sorption the fractal dimension of pores was from 2.13 to 2.50 , whereas sorption of water vapor gave the fractal dimension of pores less than 1.5 due to altering of cellulose structure under effect of water. The study the distribution of nano-scale cellulose aggregates by method of small-angle X-ray scattering permitted to calculate the fractal dimension $\mathrm{D}=2.10$ [5].

The main purpose of this research was to study the fractal characteristics of Microcrystalline Cellulose (MCC) beads with different sizes prepared by method of spray drying, which can be used as excipient in pharmaceutics and medicine, as well as filler in various composite materials.

\section{Experimental}

\section{Material}

The initial material was chemical grade cotton cellulose (99\% $\alpha$-cellulose, DP=2700) of Hercules Inc.

\section{Method of preparation beads of MCC}

Cotton cellulose was hydrolyzed with boiling $1.5 \mathrm{M}$ sulfuric acid at the acid/cellulose ratio 10 for $1 \mathrm{~h}$ followed by filtration of the acid and washing of MCC on the filter to neutral $\mathrm{pH}$ [6]. The resulting wet cake of MCC was diluted with distilled water to obtain 1-5\% dispersions, which were disintegrated in Waring blender at $15,000 \mathrm{rpm}$ for $10 \mathrm{~min}$ to break the agglomerates. To produce beads, the aqueous dispersions of MCC were spray-dried using a lab drier of Pilotech at the following conditions: feeding $10 \mathrm{ml} / \mathrm{min}$, air pressure $0.2 \mathrm{MPa}$, inlet temperature $120^{\circ} \mathrm{C}$ and outlet temperature $60^{\circ} \mathrm{C}$.

\section{Sieve analysis}

Table 1: Average radius $(R)$ of the separated MCC beads.

\begin{tabular}{|c|c|c|}
\hline Mesh & Hole diameter, $\mu \mathbf{m}$ & $\mathbf{R}, \mu \mathbf{m}$ \\
\hline $80-100$ & $149-177$ & 82 \\
\hline $140-170$ & $88-105$ & 48 \\
\hline $230-270$ & $53-63$ & 29 \\
\hline $450-635$ & $20-32$ & 13 \\
\hline
\end{tabular}

MCC beads of different sizes were separated by screening through sieves with mesh of 80-100, 140-170, 230-270 and 450635. The average radius of the beads was shown in the Table 1. With rise of the concentration of MCC dispersion from 1 to $5 \%$, an increase in the yield of larger beads was observed. 


\section{Scanning electron microscopy}

Shape of MCC beads were investigated by electron microscope Hitachi S- 4700 .

\section{Wide-angle X-ray scattering (WAXS)}

Nanostructure of MCC beads was investigated by WAXS method using Rigaku-Ultima Plus diffractometer $\left(\mathrm{CuK}_{\mathrm{a}}\right.$ - radiation, $l=0.15418 \mathrm{~nm}$ ) $[7,8]$. Lateral size (L) of cellulose nanocrystalline particles (CNP) in direction perpendicularly to [200] planes of crystalline unit cell were calculated by modified Scherrer equation taking into account the contribution of instrumental factor and lattice distortions to width of crystalline peak. Minimum radius of CNP was calculated as follows: $r=0.5 \mathrm{~L}$.

\section{Sorption method}

Sorption of hexane vapor by MCC beads was measured at $25^{\circ} \mathrm{C}$ with the use of a vacuum Mac-Ben apparatus having helical spring quartz scales [9]. The porosity (P, $\left.\frac{\mathrm{cm}^{3}}{\mathrm{~g}}\right)$ of the beads was calculated by the equation:

$$
P=\frac{V}{m} \text { (1) }
$$

where $\mathbf{V}$ is total volume of pores $\left(\mathrm{cm}^{3}\right)$ measured at relative vapor pressure $\frac{p}{p_{o}}=0.98 ; \mathbf{m}$ is mass of the dry sample $(\mathrm{g})$.

\section{Results and Discussion}

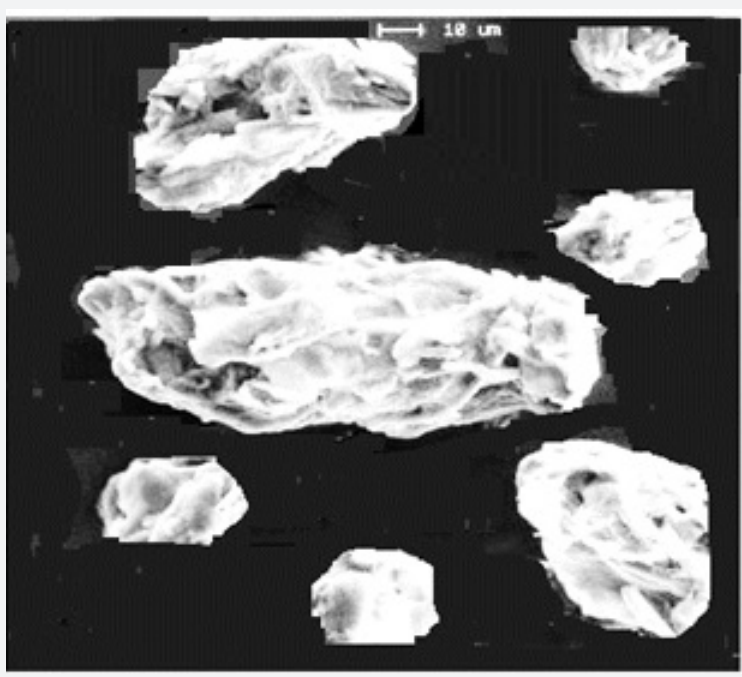

Figure 1: Image of MCC beads of different sizes.

SEM studies showed that spray-dried MCC beads have ellipsoidal or spherical shape and contain small rod-like particles (Figure 1). As known, cellulose is semicrystalline linear polysaccharide that consists of elementary nanofibrils and their bundles called microfibrils [10]. Furthermore, each nano-scale fibril is built of ordered rod-like nanocrystallites and low ordered amorphous nanodomains. The three-dimensional ordered nanocrystallites are strong and inaccessible structural elements. As against, the low-ordered amorphous domains are weak and accessible segments of the fibrils. Therefore, cleavage of amorphous domains at the acid hydrolysis leads to formation of rod-shaped nanocrystalline particles (CNP). As a result of spraydrying, the rod-shaped CNP are aggregated by their side surfaces and forms micron sized beads of microcrystalline cellulose with various average radius.

Table 2: Lateral size $(L)$ and minimum radius $(r)$ of $C N P$ in $M C C$ beads of different sizes.

\begin{tabular}{|c|c|c|}
\hline $\mathbf{R}, \boldsymbol{\mu} \mathbf{m}$ & $\mathbf{L}, \mathbf{n m}$ & $\mathbf{r}, \mathbf{n m}$ \\
\hline 82 & 6.2 & 3.1 \\
\hline 48 & 5.8 & 2.9 \\
\hline 29 & 6 & 3 \\
\hline 13 & 6.1 & 3 \\
\hline Average: & 6 & 3 \\
\hline
\end{tabular}

The structural studies showed that CNP isolated from plant biomass have lateral sizes of $4-8 \mathrm{~nm}$ and length of $100-200 \mathrm{~nm}$ [11]. As it follows from WAXS results, the average lateral size (L) of CNP made of cotton cellulose is $6 \mathrm{~nm}$ and their average radius (r) is $3 \mathrm{~nm}$ or $0.003 \mu \mathrm{m}$ (Table 2 ).

The study of vapor sorption of inert organic liquid (hexane) revealed that the porosity of MCC beads varies in the range from 0.0757 to $0.0931 \frac{\mathrm{cm}^{3}}{\mathrm{~g}}$ (Table 3). Moreover, when the average size of the beads increases, their porosity rises.

Table 3: Porosity (P) and density $(\rho)$ of MCC beads of different sizes.

\begin{tabular}{|c|c|c|c|}
\hline $\mathbf{R}, \boldsymbol{\mu m}$ & $\mathbf{R} / \mathbf{r}$ & $\mathbf{P}, \mathbf{c m} 3 \mathbf{g}$ & $\boldsymbol{\rho}, \mathbf{g} / \mathbf{c m} 3$ \\
\hline 82 & $2.73 \times 104$ & 0.0931 & 1.378 \\
\hline 48 & $1.60 \times 104$ & 0.0884 & 1.39 \\
\hline 29 & $9.67 \times 103$ & 0.0833 & 1.4 \\
\hline 13 & $4.33 \times 103$ & 0.0757 & 1.415 \\
\hline
\end{tabular}

The dependence of porosity $(\mathrm{P})$ on scale factor $(\mathrm{R} / \mathrm{r})$ can be expressed by a power-law function:

$$
\mathrm{P}=\mathrm{P}_{\mathrm{o}}(\mathrm{R} / \mathrm{r})^{\mathrm{E}-\mathrm{D}} \mathrm{p}(2)
$$

where $\mathrm{P}_{\mathrm{o}}$ is porosity of CNP, $\mathrm{D}_{\mathrm{P}}$ is fractal dimension; $\mathrm{E}=3$ is Euclidean dimension for three-dimensional space. 


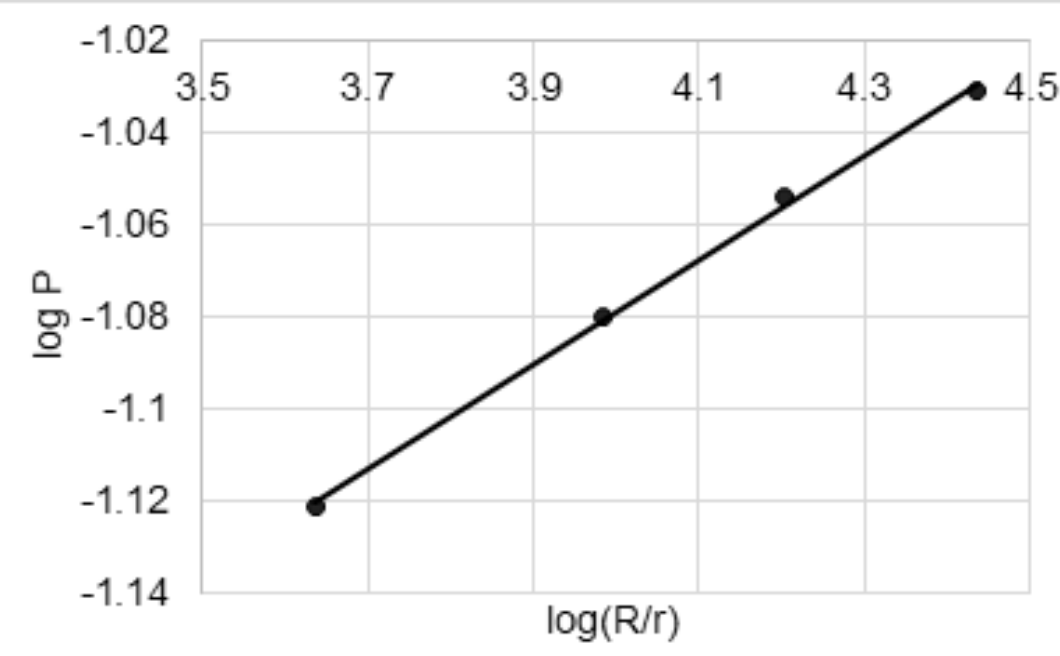

Figure 2: Linearized dependence $P=f(R / r)$ in double logarithmic coordinates.

After logarithmizing of the function (2), a linear graph was drawn (Figure 2), from which the values of $\mathrm{P}_{\mathrm{o}}=0.03\left(\frac{\mathrm{cm}}{\mathrm{g}}\right)$ and $\mathrm{D}_{\mathrm{P}}$ $=2.887$ were found.

Along with porosity, it is also possible to calculate the density of MCC beads, as follows:

$$
\rho=\left[\left(P+V_{c}\right)\right]^{-1}
$$

where $\mathrm{V}_{\mathrm{c}}=\mathrm{d}^{-1}$ is specific volume of CNP having crystallinity about $80 \%$ and true density (specific gravity) $\mathrm{d}=1.585 \mathrm{~g} / \mathrm{cm}^{3}$ [10].

Using $\rho$ values and scale factor $\left(\frac{R}{r}\right)$ (Table 3 ), the linear dependence can be obtained (Figure 3 ) by logarithmizing of the function:

$$
\rho=\mathrm{d}(\mathrm{R} / \mathrm{r})^{\mathrm{D} \rho-\mathrm{E}}
$$

From the linearized graph (Figure 3), the value of $D_{\rho}=2.986$ was calculated.

The results have shown that the small beads contain more densely packed aggregates of CNP than the large MCC beads. According to DLA-theory [2, 12-14], such structural feature indicates that the formation of MCC beads occurs via diffusionlimited aggregation process.

\section{Conclusion}

Rod-shaped crystalline nanoparticles (CNP) of cotton cellulose with radius $\mathrm{r}=3 \mathrm{~nm}$ have a compact packing with high true density (specific gravity) $\mathrm{d}=1.585 \mathrm{~g} / \mathrm{cm}^{3}$ and negligible porosity $\mathrm{P}_{0}=0.03$ $\frac{\mathrm{cm}^{3}}{\mathrm{~g}}$. During spray-drying a lateral aggregation of rod-shaped CNP occurs. Moreover, with the development of aggregation process of CNP and increase in size of the formed MCC beads, the order in the packing is distorted conforming to theory of diffusion-limited aggregation process. Consequence of this phenomenon is increase in porosity and decrease in density with the rise in size (average radius $\mathrm{R}$ ) of the beads. The dependences of porosity $(\mathrm{P})$ and density $(\rho)$ on scale factor $(R / r)$ can be expressed by the following power-law equations:

$$
P=P_{o}\left(\frac{R}{r}\right)^{E-D_{P}} \text { and } \rho=d\left(\frac{R}{r}\right)^{D \rho-E}
$$

where the fractal dimensions $\mathrm{D}_{\mathrm{P}}=2.887$ and $\mathrm{D}_{\rho}=2.986$ are close to Euclidean dimension $\mathrm{E}=3$ for three-dimensional space.

\section{References}

1. Mandelbrot BB (1982) The fractal geometry of nature. (1 $1^{\text {st }}$ Edn), W H Freeman \& Co, SanFrancisco, USA, 25(6): 34.

2. Pietronero L, Tosatti E (1986) Fractals in Physics. Elsevier, Amsterdam, Netherlands, p. 489.

3. Gou WZ, Wang Y, Huang MZ, Wan JQ Ma YW (2011) An investigation of the variation of pore structure in eucalyptus fibre during recycling. Bioresources 6(2): 1029-1042.

4. Strømme M, Mihranyan A, Ek R, Niklasson G A (2003) Fractal dimension of cellulose powders analyzed by multilayer bet adsorption of water and nitrogen. J Phys Chem B 107(51): 14378-14382.

5. Díaz M, Hernández M, Ibarra IA, Guzman A, Lara V, et al. (2017) Cellulose with a high fractal dimension is easily hydrolysable under acid catalysis. Catalysts 7(5): 162-174.

6. Ioelovich M (2018) Green chemistry of micro-and nanoparticles of plant biomass. S Asian Res J Nat Prod 1(1): 1-10.

7. Ioelovich M, Leykin A, Figovsky O (2010) Study of cellulose paracrystallinity. Bioresourcez 5(3): 1393-1407.

8. Ioelovich M (2018) Determination of distortions and sizes of cellulose nanocrystallites. Res J Nanosci Eng 2(1): 1-5.

9. Ioelovich M Leykin A (2011) Study of sorption properties of cellulose and its derivatives. Bioresources 6(1): 178-195.

10. Ioelovich M (2016) Models of supramolecular structure and properties of cellulose. J Polym Sci A 58 (6): 925-943.

11. Habibi Y, Lucia LA, Rojas OJ (2010) Cellulose nanocrystals chemistry, self-assembly and applications. Chem Rev 110(6): 3479-3500.

12. Karmanov AP, Monakov Y B (1999) Fractal structure of lignin. J Polym Sci B 41 (7): 1200-1205.

13. Bourke PD (2006) Constrained diffusion limited aggregation in three dimensions. Comput Graph 30(4): 646-649.

14. Nogueira IR, Alves SG, Ferreira SC (2011) Scaling laws in the diffusion limited aggregation of persistent random walkers. Statist Mech.Appl 290(23-24): 4087-4094. 
This work is licensed under Creative Commons Attribution 4.0 License DOI: 10.19080/AJOP.2018.02.555583

\section{Your next submission with Juniper Publishers} will reach you the below assets

- Quality Editorial service

- Swift Peer Review

- Reprints availability

- E-prints Service

- Manuscript Podcast for convenient understanding

- Global attainment for your research

- Manuscript accessibility in different formats ( Pdf, E-pub, Full Text, Audio)

- Unceasing customer service

Track the below URL for one-step submission https://juniperpublishers.com/online-submission.php 